\section{Case Reports in Ophthalmology}

Case Rep Ophthalmol 2020;11:370-376

DOI: 10.1159/000508032
Published online: July 17, 2020

(C) 2020 The Author(s)

Published by S. Karger AG, Basel www.karger.com/cop

This article is licensed under the Creative Commons Attribution-NonCommercial 4.0 International License (CC BY-NC) (http://www.karger.com/Services/OpenAccessLicense). Usage and distribution for commercial purposes requires written permission.

\title{
The Role of Optical Coherence Tomography Angiography in Ranibizumab-Treated Choroidal Neovascularization in Choroidal Osteoma
}

\author{
William J. Carroll Yi Stephanie Zhang Lee M. Jampol Manjot K. Gill \\ Department of Ophthalmology, Feinberg School of Medicine, Northwestern University, \\ Chicago, IL, USA
}

\section{Keywords}

Choroidal osteoma $\cdot$ Optical coherence tomography $\cdot$ Choroidal neovascularization

\begin{abstract}
In this study, we report the initial evaluation of choroidal neovascularization (CNV) secondary to choroidal osteoma and subsequent response to anti-vascular endothelial growth factor (anti-VEGF) treatment monitored with optical coherence tomography angiography (OCT-A). A 38-year-old female presented with an initial visual acuity of 20/150 in the left eye. Clinical examination revealed a choroidal osteoma. OCT demonstrated both subretinal and intraretinal fluid. OCT-A was performed and showed CNV. A course of ten treatments with ranibizumab showed an improvement of visual acuity to 20/30-3, improvement of subretinal and intraretinal fluid, as well as attenuation of CNV. Our report demonstrates OCT-A as a useful tool for both initial evaluation of CNV and following treatment response to anti-VEGF therapy.
\end{abstract}




\section{Case Reports in Ophthalmology}

\section{Introduction}

Choroidal osteoma (CO) is a benign, rare tumor of cancellous bone that may supplant the full thickness of the choroid $[1,2]$. It is most common in women in the third decade and its exact etiology is unknown $[1,2]$. It often presents juxtapapillary or within the macula and may have an orange to yellow appearance [1,2]. A sizable portion of these tumors exhibit slow growth and may exhibit choroidal neovascularization (CNV) or decalcification [1, 2].

CNV may be present in $19 \%$ of patients at presentation and in $31 \%$ over a 10 -year period, typically portending a poor visual prognosis [2]. CNV was seen most commonly in tumors with an irregular surface or overlying hemorrhage. Optical coherence tomography angiography (OCT-A) has been shown to be effective in evaluating CNV in patients with $\mathrm{CO}$ and those treated with anti-vascular endothelial growth factor (anti-VEGF) therapy [3-7].

OCT-A imaging of CNV secondary to CO has now been described in patients who have been responsive to bevacizumab or ranibizumab [4-7]. Our current case presents the longest follow-up in the literature of treatment with anti-VEGF and documentation with OCT-A.

\section{Case Report}

A 38-year-old female presented with a 4-month history of decreased vision in the left eye. Best-corrected visual acuity measured 20/20 in the right eye and 20/150 in the left eye. She had a $1+$ relative afferent pupillary defect in the left eye. The fundus exam in the right eye was normal. The left eye was notable for a $\mathrm{CO}$ extending under the fovea with overlying subretinal fluid on fundus exam (Fig. 1A). CO was confirmed on ultrasonography (Fig. 1C) and fluorescein angiogram (Fig. 1B) did not reveal a clear CNV membrane. Spectral-domain optical coherence tomography (SD-OCT) showed subretinal and intraretinal fluid associated with a thick choroidal lesion and abnormal retinal pigment epithelium (Fig. 1D, E). OCT-A was performed and demonstrated a CNV beneath the fovea (Fig. 1F, G). Subsequent OCT-A scans in conjunction with clinical findings (specifically visual acuity) were used to monitor CNV activity and determine the course of ranibizumab management. Following ten monthly ranibizumab injections, visual acuity had improved to 20/30-3, and the osteoma was stable. SD-OCT showed a consolidated CNV with marked decrease in subretinal and intraretinal fluid compared to initial presentation (Fig. 2). OCT-A revealed an interim decrease in both the size and flow of the CNV lesion (Fig. 3).

\section{Discussion}

In patients with CO, up to 31\% may develop secondary CNV at 10 years [2]. Therefore, within this population, $\mathrm{CNV}$ has a relatively high occurrence and is a significant cause for

visual morbidity and may portend a poor long-term visual prognosis [2]. Many reported cases of CNV and associated subretinal fluid in CO have resolved with a series of up to four anti-VEGF injections [4-7]. Our case required ten monthly injections of ranibizumab suggesting a more aggressive or refractory secondary CNV than those previously reported. As has been suggested in exudative age-related macular degeneration, differential responses in treatment may be indicative of varying three-dimensional structures of the CNV necessitating different treatment burdens and would be an avenue for future exploration and analysis [8]. 


\section{Case Reports in Ophthalmology}

Carroll et al.: OCTA in Ranibizumab-Treated CNV in Choroidal Osteoma

The role of multimodal imaging continues to refine the current understanding of the structure of CO. Enhanced depth imaging optical coherence tomography (EDI-OCT) findings have been described showing in vivo the bony structure of CO [9]. Traditionally, invasive and costly methods, such as fluorescein and indocyanine green angiography, have been used to evaluate CO for CNV [10].

High-quality OCT-A has proven to be an invaluable, non-invasive, cost-effective imaging modality for detecting and monitoring treatment response of $\mathrm{CNV}$ in $\mathrm{CO}$ as shown in our patient. Some have suggested that OCT-A may provide better visualization of the vessels and is less susceptible to degradation of the visualization of the vessels by leaking and hyperfluorescence than fluorescein angiography [7].

Our study further lends support to the usefulness of OCT-A to allow detailed assessment of both the CNV structure in en-face view and flow with cross-sectional scans. This allows for incremental, non-invasive evaluation of the CNV with each treatment to assess the efficacy of therapy with anti-VEGF agents. This case in particular demonstrates the responsiveness of $\mathrm{CNV}$ secondary to CO on OCT-A, and it further shows that some CNV are more persistent and require a longer course of treatment than has been previously described.

\section{Statement of Ethics}

In accordance with the Declaration of Helsinki, the patient gave written informed consent to the publication of this case report.

\section{Disclosure Statement}

The authors (W.J.C., Y.S.Z., L.M.J., and M.K.G.) have no relevant financial disclosures or conflicts of interest.

\section{Funding Sources}

No funding was received.

\section{Author Contributions}

All authors attest that they meet the current ICMJE criteria for authorship.

W.J.C.: Patient management, conception of study, data interpretation, literature search, manuscript writing, editing, and revision. Y.S.Z.: Literature search, manuscript writing, editing, and revision. L.M.J.: Patient management, data interpretation, manuscript editing, revision, and final approval. M.K.G.: Patient management, conception of study, data interpretation, literature search, manuscript writing, editing, revision, and final approval. 


\section{Case Reports in Ophthalmology}

\section{References}

1 Alameddine RM, Mansour AM, Kahtani E. Review of choroidal osteomas. Middle East Afr J Ophthalmol. 2014 Jul-Sep;21(3):244-50.

2 Shields CL, Sun H, Demirci H, Shields JA. Factors predictive of tumor growth, tumor decalcification, choroidal neovascularization, and visual outcome in 74 eyes with choroidal osteoma. Arch Ophthalmol. 2005 Dec;123(12):1658-66.

3 Pierro L, Marchese A, Gagliardi M, Introini U, Battaglia Parodi M, Casalino G, et al. Choroidal excavation in choroidal osteoma complicated by choroidal neovascularization. Eye (Lond). 2017 Dec;31(12):1740-3.

4 Shen C, Yan S, Du M, Zhao H, Shao L, Hu Y. Assessment of choroidal osteoma complicating choroidal neovascularization by optical coherence tomography angiography. Int Ophthalmol. 2018 Apr;38(2):787-92.

5 Mihailovic N, Alnawaiseh M, Merté RL, Eter N. [Choroidal neovascularisation in a patient with choroidal osteoma visualized by OCT angiography]. Ophthalmologe. 2017 Sep;114(9):843-7.

6 Clemente-Tomás R, Cerdà-Ibáñez M, Gargallo-Benedicto A, Marín-Lambíes C, Manfreda-Domínguez L, DuchSamper AM. Choroidal osteoma with choroidal excavation and associated neovascular membrane: an OCT angiography study. Arch Soc Esp Oftalmol. 2018 May;93(5):242-5.

7 Cennamo G, Romano MR, Iovino C, Velotti N, Breve MA, de Crecchio G, et al. OCT angiography in choroidal neovascularization secondary to choroidal osteoma. Acta Ophthalmol. 2017 Mar;95(2):e152-4.

8 Nesper PL, Soetikno BT, Treister AD, Fawzi AA. Volume-Rendered Projection-Resolved OCT Angiography: 3D Lesion Complexity Is Associated With Therapy Response in Wet Age-Related Macular Degeneration. Invest Ophthalmol Vis Sci. 2018 Apr;59(5):1944-52.

9 Shields CL, Manalac J, Das C, Saktanasate J, Shields JA. Review of spectral domain-enhanced depth imaging optical coherence tomography of tumors of the retina and retinal pigment epithelium in children and adults. Indian J Ophthalmol. $2015 \mathrm{Feb}$;63(2):128-32.

10 Lafaut BA, Mestdagh C, Kohno T, Gaudric A, De Laey JJ. Indocyanine green angiography in choroidal osteoma. Graefes Arch Clin Exp Ophthalmol. 1997 May;235(5):330-7. 


\section{Case Reports in Ophthalmology}

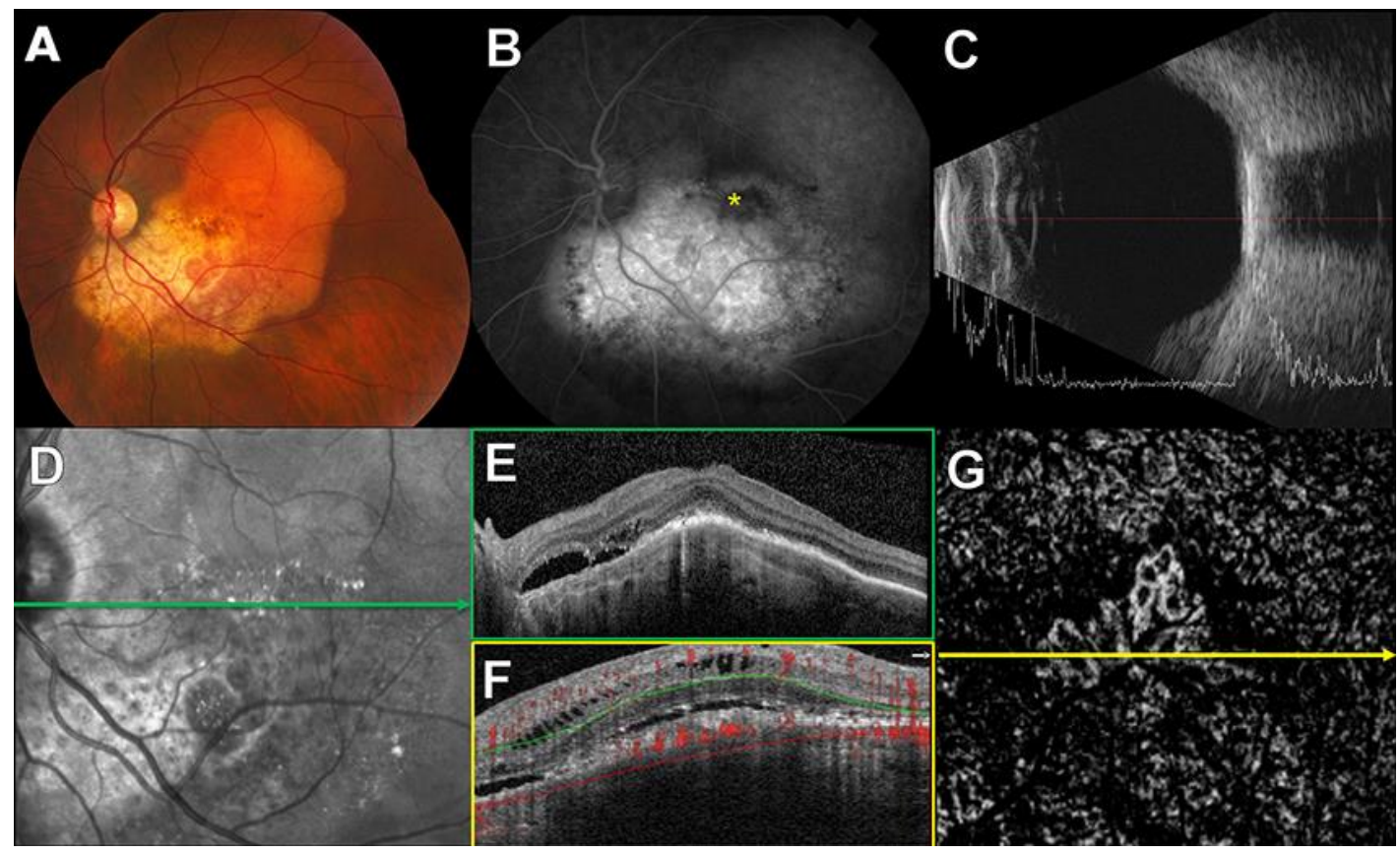

Fig. 1. Multimodal imaging at initial presentation. Color fundus photography (A) notable for juxtapapillary CO extending beneath the fovea with diffuse hyperfluorescence on late-stage fluorescein angiography (B) with no clear evidence of CNV membrane. Yellow asterisk (B) marks the location of CNV found on en-face OCT-A in panel G. B-scan ultrasonography with a reflective choroidal mass in the posterior pole with acoustic shadowing and high-intensity echo spikes on A scan (C). Infrared image (D) with corresponding SD-OCT (E) showing choroidal thickening and overlying subretinal and intraretinal fluid. OCT-A B-scan (F) and enface image at the outer retina (G) demonstrating $\mathrm{CNV}$ at the location marked by an asterisk in panel B. 
Case Reports in Ophthalmology
Case Rep Ophthalmol 2020;11:370-376

DOI: $10.1159 / 000508032$

(c) 2020 The Author(s). Published by S. Karger AG, Basel www.karger.com/cop

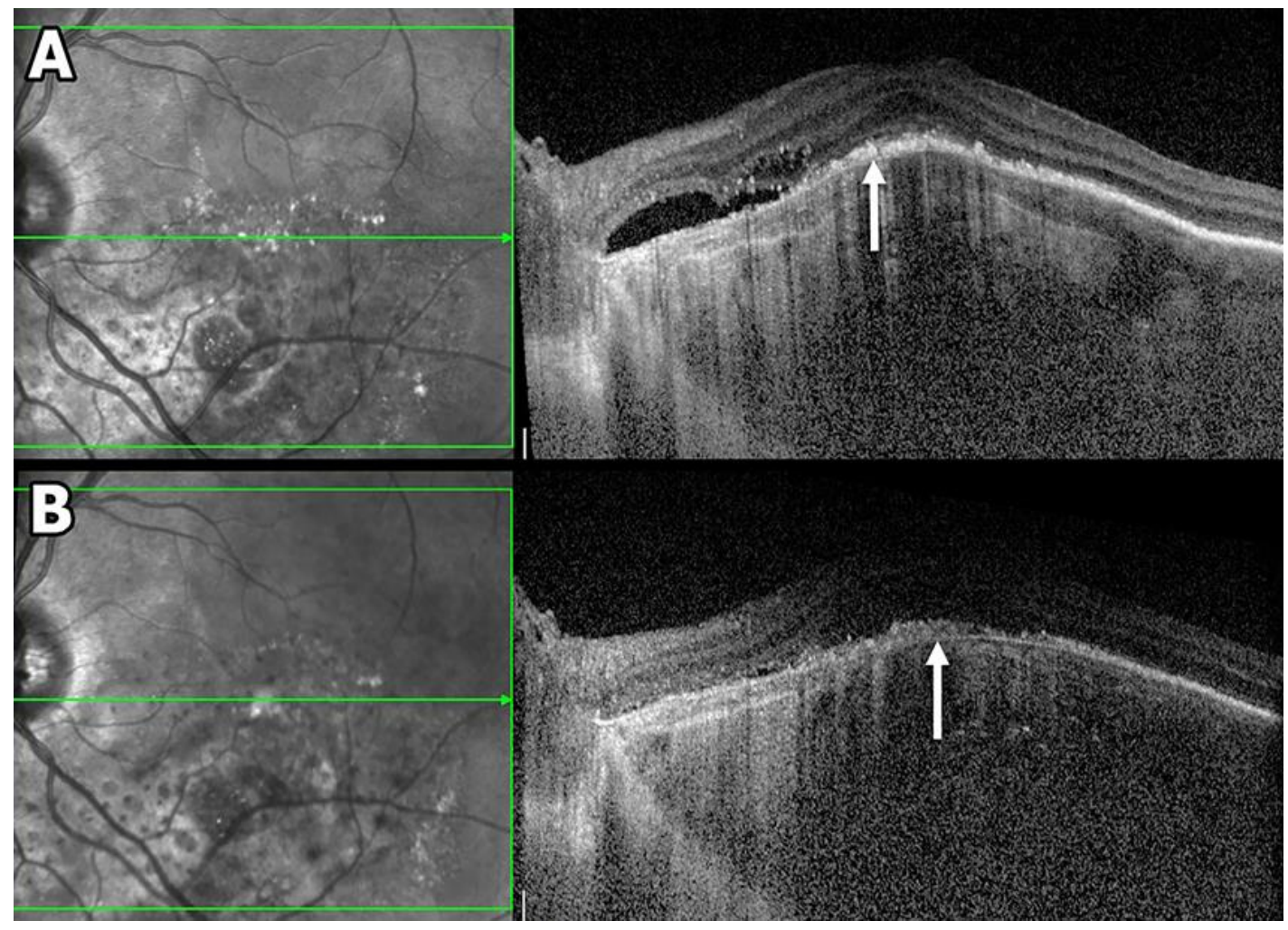

Fig. 2. Enhanced depth imaging SD-OCT at presentation (A) and at the 10-month follow-up (B) demonstrating consolidation of CNV (arrow) with reduction in associated subretinal and intraretinal fluid. 
Case Reports in Ophthalmology
Case Rep Ophthalmol 2020;11:370-376

DOI: $10.1159 / 000508032$

(c) 2020 The Author(s). Published by S. Karger AG, Basel www.karger.com/cop

Carroll et al.: OCTA in Ranibizumab-Treated CNV in Choroidal Osteoma

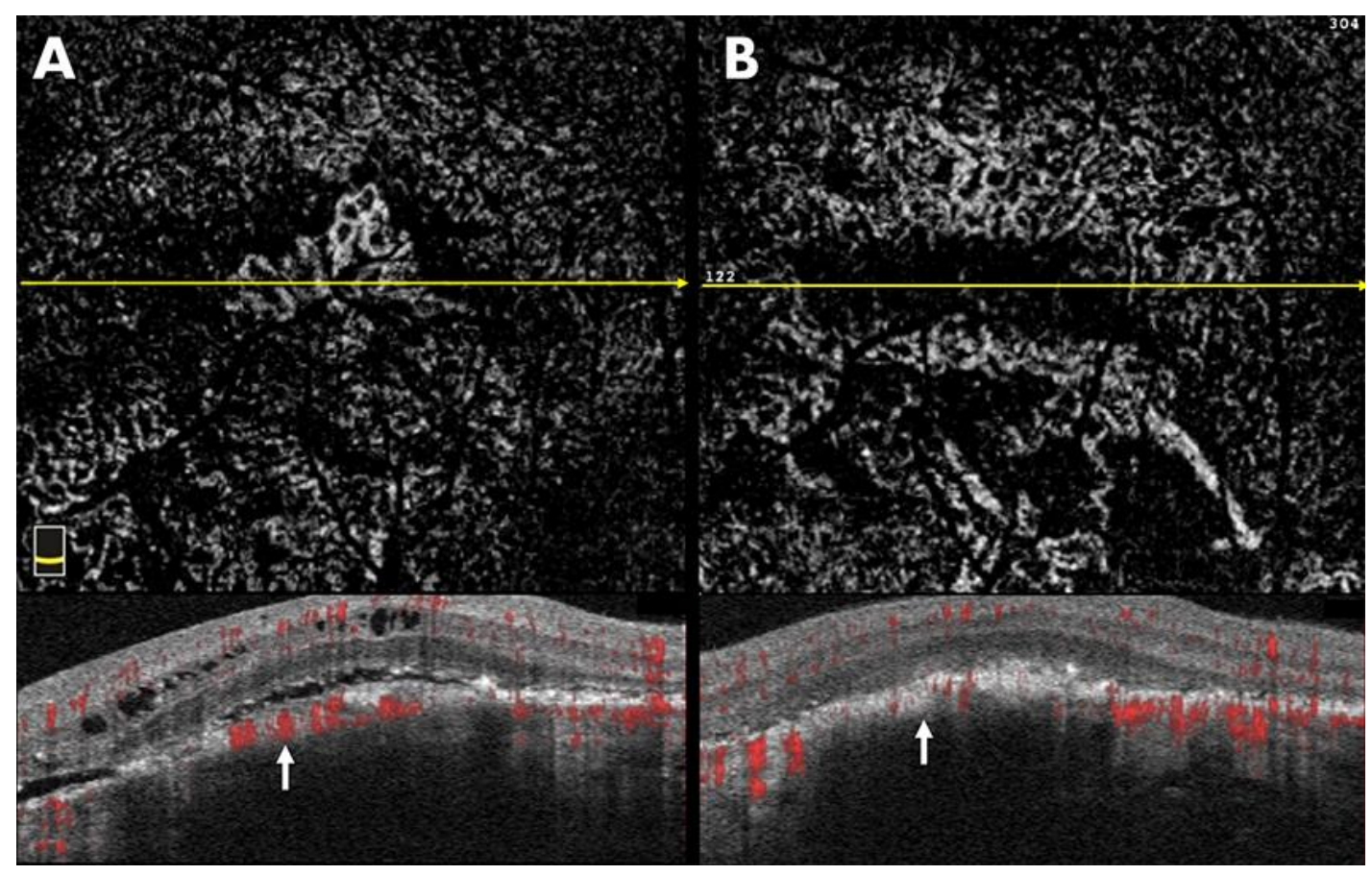

Fig. 3. OCT-A at presentation (A) and at the 10-month follow-up (B). Note the reduction in both the size of $\mathrm{CNV}$ on en-face outer retina images and flow on the B-scan images (arrows). 